\title{
Unravelling zoonotic diseases in Australia
}

Keith Eastwood, Peter D Massey, Siobhan M Mor, Katrina Bosward

THIS EDITION OF Australian Journal of General Practice (AJGP) contains five articles covering zoonoses encountered in Australia: Q fever, ${ }^{1}$ brucellosis, ${ }^{2}$ psittacosis ${ }^{3}$ and leptospirosis, ${ }^{4}$ and Australian bat lyssavirus exposure. ${ }^{5}$ An article published in Australian Family Physician in 2014, ${ }^{6}$ on recognition, diagnosis and management of common Australian zoonoses, completes the set.

The papers were coordinated through The Regional One Health Partnership (One Health), an informal group of professionals consisting of clinicians, veterinarians, academics, epidemiologists, public health practitioners, environmental scientists, wildlife health specialists, pathologists and others. One Health acknowledges the interconnection between human health, animal health and the environment, and provides a holistic approach to the understanding of health issues. Professionals combine skills, legislative authority and data access to monitor and address shared risks and interests through collaboration on issues such as communicable disease clusters, animal die-offs, toxic spills, epidemiological and research studies, policy development and education resources.

A large proportion of communicable diseases have an animal origin, including salmonellosis, campylobacteriosis, cryptosporidiosis and enteropathogenic Escherichia coli infections, while Ebola, severe acute respiratory syndrome, Hendra and tularaemia are examples of emerging, rare zoonoses. More than two-thirds of emerging diseases have an animal association. 7 The articles included in this issue of AJGP cover the more 'traditional' zoonotic diseases in Australia, which are notifiable in most states and territories.
Understanding the epidemiology of zoonoses is improving as surveillance systems refine the collection of risk exposure information, and agencies, research organisations and other partnerships combine investigative efforts in the spirit of One Health.

Recent findings indicate more obtuse risk pathways for zoonotic diseases than previously considered. These include lawn mowing 'aerosolisation' of wildlife and bird droppings (eg Q fever, psittacosis), feral pig hunting (eg brucellosis), people living on stock transport routes (eg Q fever), and involvement in the birthing of horses, cats, cattle and other animals (eg Q fever, psittacosis). It requires patience and skill to collect patient exposure information down to this level but is worth the effort as people with zoonotic disease often present with signs and symptoms that are difficult to differentiate from other conditions; yet prompt, appropriate treatment may prevent ongoing sequelae and complications.

Q fever, brucellosis, leptospirosis and psittacosis (along with other zoonotic diseases such as rickettsial diseases) are bacterial infections and respond to appropriate antibiotic therapy. Multiplex polymerase chain reaction tests are now available that cover multiple zoonotic agents and could be a useful diagnostic tool to detect early onset disease.

Apart from the articles in this edition of AJGP, many primary healthcare networks provide point-of-care decision-making resources and referral networks on their 'HealthPathways'8 or 'Map of Medicine' sites. Additionally, the regional public health unit should be considered as a reference point for disease information and advice, as it can provide current data on local zoonosis risk and incidence, and connect GPs to agricultural or wildlife agencies for further assistance. In the future, there may be a process to refer people between veterinarians and general practitioners, to assess and reduce the risk of zoonoses. ${ }^{9}$

\section{Authors}

Keith Eastwood DrPH, MAppEpid, BAppSci, Epidemiologist, Hunter New England Population Health; Adjunct Senior Lecturer, University of Newcastle, NSW. keith.eastwood@hnehealth. nsw.gov.au

Peter D Massey DrPH, GCPH, RN, Program Manager Health Protection, Hunter New England Population Health; and Adjunct Associate Professor, School of Health, University of New England, NSW

Siobhan M Mor BSc (Vet), BVSc, PhD, Senior Lecturer in Epidemiology (One Health), University of Sydney, NSW

Katrina Bosward BSc (Vet), BVSc, PhD,

DiplVetClinStud, GradCert (Higher Ed), Senior Lecturer in Veterinary Microbiology, University of Sydney, School of Veterinary Science, NSW

\section{References}

1. Eastwood K, Graves SR, Massey PD, Bosward K, van den Berg D, Hutchinson P. Q fever: A rural disease with potential urban consequences. Aust $J$ Gen Pract 2018;47(3):112-16.

2. Mor SM, Wiethoelter AK, Massey PD, Robson J, Wilks K, Hutchinson P. Pigs, pooches and pasteurisation: The changing face of brucellosis in Australia. Aust J Gen Pract 2018;47(3):99-103.

3. Taylor K, Durrheim D, Massey PD, Hughes K, Heller J, Jones B. An atypical case of typical pneumonia. Aust J Gen Pract 2018;47(3):119-21.

4. Lau CL, Townell N, Stephenson E, van den Berg D, Craig SB. Leptospirosis - An important zoonosis acquired through work, play and travel. Aust J Gen Pract 2018;47(3):105-10.

5. Merritt T, Taylor K, Cox-Witton K, et al. Australian Bat Lyssavirus. Aust J Gen Pract 2018;47(3):93-96.

6. Gunaratnam P, Massey P, Eastwood K, et al. Diagnosis and management of zoonoses - A tool for general practice. Aust Fam Physician 2014;43(3):124-28.

7. Taylor LH, Latham SM, Woolhouse ME. Risk factors for human disease emergence. Philos Trans R Soc Lond B Biol Sci (2001); 356: 983-89.

8. Hunter New England Central Coast Primary Health Care Network. What is HealthPathways? NSW: HNECCPHN, 2018. Available at www. hneccphn.com.au/programs-resources/ healthpathways [Accessed 11 February 2018].

9. Speare R, Mendez D, Judd J, Reid S, Tzipori S, Massey PD. Willingness to consult a veterinarian on physician's advice for zoonotic diseases: A formal role for veterinarians in medicine? PLoS One 2015;10(8):e0131406. 